\title{
Water induced variety of arsenic(III) oxide intercalates with alkali chlorides
}

\author{
Piotr A. Guńka \\ Faculty of Chemistry, Warsaw University of Technology, Warszawa, Poland \\ piogun@ch.pw.edu.pl
}

Arsenic(III) oxide has been known to form stoichiometric compounds with potassium and ammonium halides since the $19^{\text {th }}$ century but they have not been structurally charaterized until the middle of the $20^{\text {th }}$ century[1-4]. It was found that the compounds are intercalation compounds in which like-charged ions form alternating layers which are separated by electroneutral $\mathrm{As}_{2} \mathrm{O}_{3}$ layers (see Figure 1). This type of compounds have been found in nature as minerals, for instance, lucabindiite [5]. In case of intercalates with ammonium and potassium cations the layers are hexagonal and non-corrugated, whereas for smaller sodium cations the arsenic(III) oxide layers are corrugated and exhibit lower symmetry. Herein, we present the synthesis methods and structural charaterization of the first $\mathrm{As}_{2} \mathrm{O}_{3}$ intercalates with potassium, rubidium and cesium chlorides containing water molecules in their crystal structure: $\mathrm{MCl}^{\circ} \mathrm{As}_{2} \mathrm{O}_{3} \cdot 1 / 2 \mathrm{H}_{2} \mathrm{O}($ for $\mathrm{M}=\mathrm{K}, \mathrm{Rb}, \mathrm{Cs}$ ) and $\mathrm{KCl} \cdot \mathrm{As}_{2} \mathrm{O}_{3} \cdot 3 \mathrm{H}_{2} \mathrm{O}$. The compounds are not only studied by single-crystal X-ray diffraction but also by solid state NMR spectroscopy and ATR-FTIR. The crystal structure determination of $\mathrm{KCl} \cdot \mathrm{As}_{2} \mathrm{O}_{3} \cdot 1 / 2 \mathrm{H}_{2} \mathrm{O}$ permitted for the correction proposal of $\mathrm{NH}_{4} \mathrm{Cl} \cdot \mathrm{As}_{2} \mathrm{O}_{3} \cdot 1 / 2 \mathrm{H}_{2} \mathrm{O}$ crystal structure.

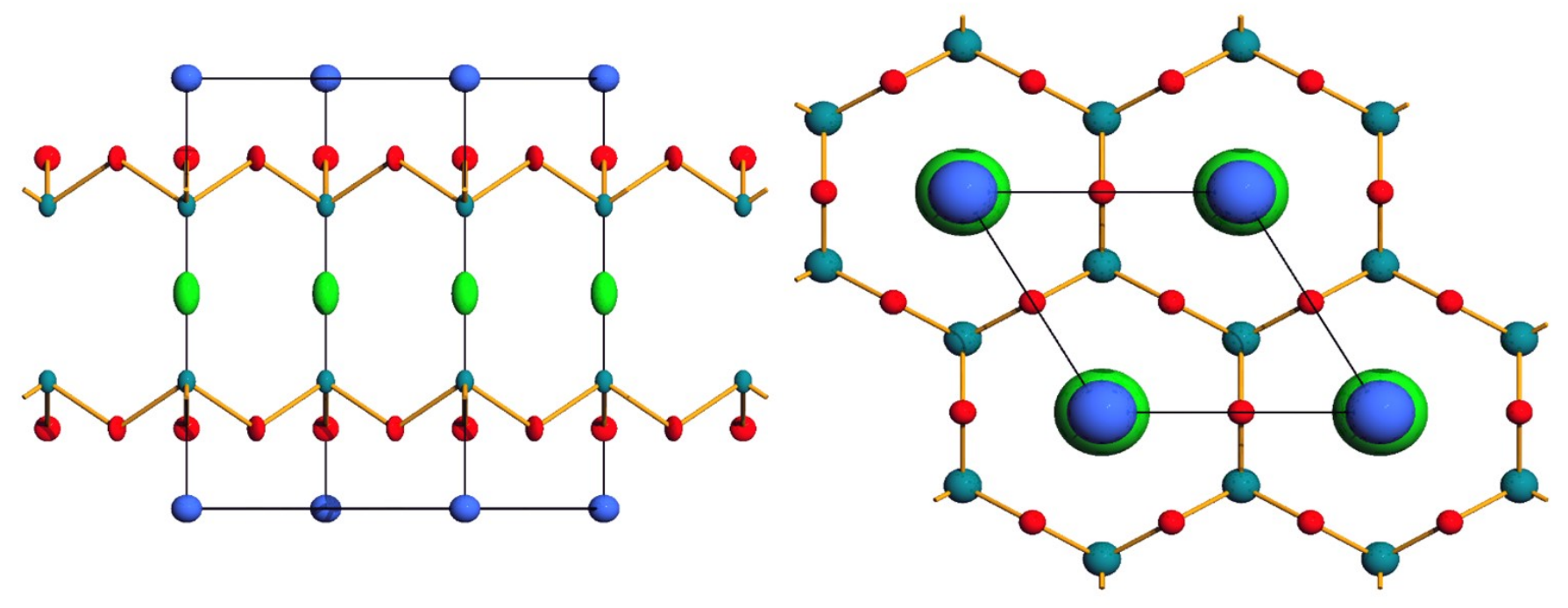

Figure 1. Crystal structure of $\mathrm{KCl} \cdot 2 \mathrm{As}_{2} \mathrm{O}_{3}$. View along [120] (left) and [001] (right). Anisotropic displacement parameters at 50\% probability level are shown in the left and ball-and-stick model is used in the right. $\mathrm{As}, \mathrm{K}, \mathrm{Cl}$ and $\mathrm{O}$ atoms are colored dark green, blue, light green and red, respectively.

[1] Rüdorff, F. (1886). Ber. Dtsch. Chem. Ges. 19, 2668-2679.

[2] Edstrand, M. \& Blomqvist, G. (1955). Arkiv för kemi. 8, 245-256.

[3] Pertlik, F. (1987). J. Solid State Chem. 70, 225-228.

[4] Pertlik, F. (1988). Monatsh. Chem. 119, 451-456.

[5] Garavelli, A., Mitolo, D., Pinto, D. \& Vurro, F. (2013). Am. Mineral. 98, 470-477.

Keywords: intercalation compounds; arsenic(III) oxide; alkali halides 